\title{
BMJ Open Contributions of maternal and paternal adiposity and smoking to adult offspring adiposity and cardiovascular risk: the Midspan Family Study
}

\author{
T S Han, ${ }^{1}$ C L Hart, ${ }^{2}$ C Haig, ${ }^{3} \mathrm{~J} \mathrm{Logue},^{4}$ M N Upton, ${ }^{5}$ G C M Watt, ${ }^{2}$ M E J Lean ${ }^{6}$
}

To cite: Han TS, Hart CL, Haig $\mathrm{C}$, et al. Contributions of maternal and paternal adiposity and smoking to adult offspring adiposity and cardiovascular risk: the Midspan Family Study. BMJ Open 2015;5:e007682. doi:10.1136/bmjopen-2015007682

- Prepublication history for this paper is available online. To view these files please visit the journal online (http://dx.doi.org/10.1136/ bmjopen-2015-007682).

Received 16 January 2015 Revised 7 August 2015 Accepted 7 October 2015

CrossMark

For numbered affiliations see end of article.

Correspondence to

TS Han;

t.s.han@doctors.org.uk

\section{ABSTRACT}

Objective: Obesity has some genetic basis but requires interaction with environmental factors for phenotypic expression. We examined contributions of gender-specific parental adiposity and smoking to adiposity and related cardiovascular risk in adult offspring.

Design: Cross-sectional general population survey.

Setting: Scotland.

Participants: 1456 of the 1477 first generation families in the Midspan Family Study: 2912 parents

(aged 45-64 years surveyed between 1972 and 1976)

who had 1025 sons and 1283 daughters, aged 30-59 years surveyed in 1996.

Main measures: Offspring body mass index (BMI), waist circumference (WC), cardiometabolic risk (lipids, blood pressure and glucose) and cardiovascular disease as outcome measures, and parental BMI and smoking as determinants. All analyses adjusted for age, socioeconomic status and family clustering and offspring birth weight.

Results: Regression coefficients for BMI associations between father-son (0.30) and mother-daughter $(0.33)$ were greater than father-daughter $(0.23)$ or motherson (0.22). Regression coefficient for the non-genetic, shared-environment or assortative-mating relationship between BMls of fathers and mothers was 0.19. Heritability estimates for BMI were greatest among women with mothers who had BMI either $<25$ or $\geq 30 \mathrm{~kg} / \mathrm{m}^{2}$. Compared with offspring without obese parents, offspring with two obese parents had adjusted OR of 10.25 (95\% Cl 6.56 to 13.93) for having WC $\geq 102 \mathrm{~cm}$ for men, $\geq 88 \mathrm{~cm}$ women, $2.46(95 \% \mathrm{Cl} 1.33$ to 4.57$)$ for metabolic syndrome and $3.03(95 \% \mathrm{Cl}$ 1.55 to 5.91 ) for angina and/or myocardial infarct $(\mathrm{p}<0.001)$. Neither parental adiposity nor smoking history determined adjusted offspring individual cardiometabolic risk factors, diabetes or stroke. Maternal, but not paternal, smoking had significant effects on WC in sons (OR=1.50; $95 \% \mathrm{Cl} 1.13$ to 2.01) and daughters ( $\mathrm{OR}=1.42 ; 95 \% \mathrm{Cl} 1.10$ to 1.84 ) and metabolic syndrome $\mathrm{OR}=1.68 ; 95 \% \mathrm{Cl} 1.17$ to 2.40 ) in sons.

Conclusions: There are modest genetic/epigenetic influences on the environmental factors behind adverse adiposity. Maternal smoking appears a specific hazard

\section{Strengths and limitations of this study}

- This study included a large number of wellcharacterised participants in a stable population, with high response rates $(>70 \%)$.

- Its design allowed, unusually and importantly, outcome analysis among offspring as adults, with relevant data for analysis of familial obesity and related diseases and risk factors.

- At the time of questionnaire completion, the ages of offspring (mean 45, SD 6 years) meant that prevalence of cardiovascular disease was still relatively low, particularly in women, so conclusions can only be drawn for early-onset coronary heart disease, and true associations with coronary heart disease may still exist.

on obesity and metabolic syndrome. A possible epigenetic mechanism linking maternal smoking to obesity and metabolic syndrome in offspring is proposed. Individuals with family histories of obesity should be targeted from an early age to prevent obesity and complications.

\section{INTRODUCTION}

The prevalence of obesity worldwide has increased relentlessly over the past three decades, consuming enormous amount of healthcare resources, directly and indirectly. ${ }^{1}$ Excess body fatness and central fat accumulation, as reflected by high body mass index (BMI) or large waist circumference (WC), has consistently been shown to relate to metabolic disturbances which promote cardiovascular disease and premature death, a variety of other morbidities and disabilities, and poor quality of life. ${ }^{34}$

Obesity results from energy imbalance, when energy intake from foods is relatively greater than energy expenditure (mainly physiological metabolism and physical 
activity). Little is known about life-course factors (physical or social exposures during different stages of growth and development from gestation, early childhood to later adult life) behind energy imbalance. Heritability of BMI is high, especially in twin studies, ${ }^{5}$ but the relative importance of genetic make-up that predisposes individuals to increased appetite or reduced metabolism is disputed. Ultimately, genes must interact with environmental factors affecting food intake and physical activity. ${ }^{6}$

Birth weight, either low or high, has been shown to associate with increased central fat accumulation ${ }^{7}$ and a number of health problems including hypertension, diabetes mellitus and cardiovascular disease in adult life. ${ }^{8}$ The possibility of epigenetic programming through fetal exposures in pregnancy is increasingly under scrutiny. Animal studies show a variety of maternal factors affecting energy balance and body fat, can be transmitted to offspring through altered DNA methylations, occurring predominantly at position C5 of cytosine in cytosineguanine dinucleotides in DNA, and other factors and similar processes appear to operate in humans. ${ }^{9}$

The major health consequences from overweight and obesity include the constellation of clinical abnormalities elevating cardiovascular risks characterised as the preventable, and reversible, metabolic syndrome. ${ }^{10}{ }^{11}$ With elevated WC as its central component, metabolic syndrome approximately doubles the risk of type 2 diabetes, cardiovascular disease and mortality. ${ }^{12}{ }^{13}$ Not all obese people develop the features of metabolic syndrome, so other genetic/epigenetic and environmental factors must be involved. One of these is smoking, which aggravates all features of metabolic syndrome. ${ }^{14}$

A number of studies have demonstrated maternal smoking to associate with offspring adiposity in adulthood $^{15-18}$ and parental BMI to associate with offspring adiposity in childhood ${ }^{19-22}$ and also later in life. ${ }^{23}$ Parental socioeconomic factors have also been shown to influence offspring obesity status. ${ }^{24}$ In two previous studies from the Midspan Family Study, we have shown that parental BMI correlated highly with adult offspring BMI $^{25}{ }^{26}$ with a upward shift of BMI by $2-3 \mathrm{~kg} / \mathrm{m}^{2}$ in the most overweight $5 \%$ of the population. ${ }^{26}$ The present study further analysed the effects of parental smoking and offspring birth weight on adult offspring body fat and fat distribution. We are not aware if any previous family studies of this kind have been conducted to investigate the influences of parental, especially maternal, lifestyle factors such as smoking and socioeconomic status on adult offspring obesity. Given evidence from existing literature, it is therefore logical to examine adiposity of adult offspring, males and females separately, in conjunction with birth weight, obesity-related complications including cardiometabolic risk factors and cardiovascular disease as health consequences of paternal and maternal exposure factors (BMI and smoking habits).

The present study aimed to identify factors which operate through mothers, specifically, so potentially through epigenetic mechanisms. We investigated separately the contributions of paternal and maternal influences, from their BMI and smoking, on offspring adiposity assessed by BMI and WC, cardiometabolic risks and clinical cardiovascular disease.

\section{METHODS}

\section{Study design, setting and participants}

The Midspan Family Study is a general population survey of 1477 Caucasian families in Renfrew and Paisley (Scotland), which included 15402 participants in the first, parental, generation (aged 45-64 years) surveyed between 1972 and 1976. In the second generation, 2338 offspring (1040 sons and 1298 daughters) aged 3059 years were surveyed in 1996 from an eligible population of 3202 offspring aged 30-59 years who lived locally. ${ }^{27}$ There were 864 eligible offspring who did not take part in the study and 1358 ineligible for the study. After exclusion of 30 step and adopted children, there were 1456 families, 2912 parents with 2308 biological offspring ( $\mathrm{n}=1025$ sons and 1283 daughters) available for data analysis. Non-participating offspring included those aged $<30$ and $>59$ years, those who had left the area (>30 miles) and those who had not left the area but decided not to take part therefore the average number of offspring recruited per family (1.6) is below the UK national average of 2.1 children born per family in $1951 .^{28}$ Parents of the migrants non-participants and parents of offspring participants in the present study had similar BMI, ${ }^{26}$ so there is no evidence of 'migrants being leaner'.

\section{Anthropometry}

In the offspring study, height was measured in the Frankfort plane to the nearest millimetre using stadiometer (Holtain Ltd, Crymych, UK) and weight to the nearest $0.1 \mathrm{~kg}$ using digital scales (Seca, Hamburg, Germany). In the parental study, height was measured to the nearest centimetre and weight was measured to the nearest kilogram. All participants were measured without shoes and wearing indoor clothes. BMI was derived as weight $(\mathrm{kg})$ divided by height squared $\left(\mathrm{m}^{2}\right)$ to determine lean $\left(<25 \mathrm{~kg} / \mathrm{m}^{2}\right)$, overweight $(25-$ $\left.29.9 \mathrm{~kg} / \mathrm{m}^{2}\right)$ and obese $\left(\geq 30 \mathrm{~kg} / \mathrm{m}^{2}\right)$ categories. ${ }^{29}$ Among offspring, WC was measured at midpoint between lowest rib margin and superior anterior suprailiac crest using non-stretchable tape measure ${ }^{29}$ and used to categorise by action levels as adopted for diagnosis of metabolic syndrome: action level 1: $94 \mathrm{~cm}$ in men, $80 \mathrm{~cm}$ in women; action level 2: $102 \mathrm{~cm}$ in men, $88 \mathrm{~cm}$ in women. ${ }^{30}$

\section{Cardiometabolic risk factors, cardiovascular disease and diabetes mellitus}

Examinations were carried out in clinics by research nurses to assess the following cardiometabolic risk factors: total and high-density lipoprotein (HDL) 
cholesterol, triglycerides and blood glucose were measured from non-fasting venous blood samples. systolic (first Korotkoff sound) and diastolic (fifth Korotkoff sound) blood pressure (BP) were measured in left arm of the offspring in sitting position and rested for at least 5 min using sphygmomanometer (Dinamap 8100, Kritikon, Tampa, Florida, USA). Clinical history of angina, myocardial infarct, strokes and diabetes mellitus were recorded. People who scored 1 or 2 on the sixpoint Rose Angina Questionnaire ${ }^{31}$ were considered to have angina. Previous myocardial infarct was defined on the basis of self-reported clinical history and/or ECG evidence, identifying cardiac ischaemia or previous myocardial infarct on a score of 1 or 2 on a four-point scale (1=definite, $2=$ probable, $3=$ possible and $4=$ =none). Metabolic syndrome was defined according to International Diabetes Federation as WC above action level 1 ( $\geq 94 \mathrm{~cm}$ in men, $\geq 80 \mathrm{~cm}$ in women) with at least two features of hypertension (systolic $\geq 130$ or diastolic $\mathrm{BP} \geq 85 \mathrm{~mm} \mathrm{Hg})$, hypertriglyceridaemia $(\geq 1.7 \mathrm{mmol} / \mathrm{L})$, low HDL cholesterol $(<1.03 \mathrm{mmol} / \mathrm{L}$ in men and $<1.29 \mathrm{mmol} / \mathrm{L}$ in women) or hyperglycaemia $(\geq 5.6 \mathrm{mmol} / \mathrm{L}){ }^{10}$

\section{Socioeconomic and lifestyle factors}

Parents and subsequently offspring completed a detailed questionnaire including information on smoking (never, current or former) and occupation. Six levels of socioeconomic classes were determined from occupation and coded according to the Registrar General's classification, and were dichotomised into non-manual (social classes I, II or III-non-manual) and manual (III-manual, IV and V) for analysis. ${ }^{32}$

\section{Birth weight}

Birth weight, obtained either from birthweight records from hospital ledgers $(n=1178)$ or recalled $(n=673)$ birth weight from offspring in the questionnaire, was available for 793 male and 1058 female offspring who were analysed as subsets. Tertiles of birth weight were created to assess its association with offspring obesity and health risk measures. Birth weight tertile 2 was used as reference group since previous studies have indicated that either low or high birth weight is associated with increased health risk in adult life. ${ }^{8}$

\section{Statistical analysis}

Influences of parental BMI on offspring BMI were assessed by regression coefficients and $95 \%$ CIs obtained from linear mixed effects model with maximum likelihood, adjusting for family clustering, offspring and parental age, smoking status (either current or former smokers) and social class (manual or non-manual). These lifestyle factors were selected as confounding factors on the basis of their strong associations with adiposity. ${ }^{33}$ Because of their high covariance $(\mathrm{r}=0.90)$, analyses of WC in offspring were not adjusted for offspring BMI to avoid multicollinearity that could result in biased estimations: BMI and WC are both principally estimates of total body fat, although WC does convey some additional influence from intra-abdominal fat deposition when the body fat range is relatively narrow. ${ }^{30}$ Coefficients for offspring BMI regressed on mid-parental BMI (average of parents' BMI) were calculated to estimate heritability $\left(\mathrm{h}^{2}\right) .{ }^{34}$ The $\chi^{2}$ test was used to assess differences between proportions of offspring obesity in different categories of parental obesity. Generalised estimating equations were used to estimate ORs of the risk of offspring for having BMI $\geq 25 \mathrm{~kg} / \mathrm{m}^{2}$ or $\geq 30 \mathrm{~kg} / \mathrm{m}^{2}$ and WC above action level 1 (men: $\geq 94 \mathrm{~cm}$, women: $\geq 80 \mathrm{~cm}$ ) or above action level 2 (men: $\geq 102 \mathrm{~cm}$, women: $\geq 88 \mathrm{~cm}$ ), angina and myocardial infarct. Most data analysis was performed separately for male and female offspring, adjusted for family clustering and the confounding factors aforementioned, with additional adjustment for offspring BMI in the analysis of angina and myocardial infarct. Additional adjustment for birth weight was also made in subgroup analysis. Both offspring sexes were analysed together only for generalised estimating equations to estimate ORs, adjusted for sex, for angina and myocardial infarct, because of the relatively low numbers of cases with the condition. Most variables had no or few missing data, except for HDL cholesterol (16\%), metabolic syndrome $(16.8 \%)$ and birth weight $(19.8 \%)$, which were handled in analysis using a 'listwise deletion of missing data' approach. ${ }^{35}$ Analyses were performed using SPSS V.22.0 (SPSS Inc, Chicago, Illinois, USA). Statistical significance was accepted when $\mathrm{p}<0.05$.

\section{RESULTS}

Participants' demographic and clinical characteristics are shown in table 1 as descriptive statistics. At the times of surveys, the mean age of fathers was 55 years, mothers 53 years, and offspring 45 years. Mean BMI of fathers, mothers and daughters were almost identical $\left(26 \mathrm{~kg} / \mathrm{m}^{2}\right)$ while that of male offspring was higher by $0.5 \mathrm{~kg} / \mathrm{m}^{2}$, on average, despite the male offspring being 5-10 years younger than their parents at the time of survey. The prevalence of obesity (BMI $\geq 30 \mathrm{~kg} / \mathrm{m}^{2}$ ) was higher in offspring than in parents. Male offspring had larger WC, higher levels of triglycerides, lower HDL cholesterol, higher blood glucose and BP and higher proportion of smoking history and myocardial infarct than female offspring. Similar rates of angina among offspring were reported by both sexes.

Table 2 shows the strengths of associations between parental and offspring BMI indicated by regression coefficients $(\beta)$ : there were significant associations between parents and offspring of either sex. In model 1, adjusted for family clustering, parental and offspring age, smoking status and social class showed offspring BMI had greater regression coefficients for associations between father-son $(\beta=0.35)$ and mother-daughter $(\beta=0.33)$ than father-daughter $(\beta=0.29)$ or mother-son 
Table 1 Descriptive statistics showing characteristics of parents and offspring from the Midspan Family Study

\begin{tabular}{|c|c|c|c|c|c|}
\hline & Mean & SD & Mean & SD & $\begin{array}{l}\text { Missing cases } \\
\text { n (\%) }\end{array}$ \\
\hline & \multicolumn{2}{|c|}{ Fathers $(n=1456)$} & \multicolumn{2}{|c|}{ Mothers $(n=1456)$} & \\
\hline Age (years) & 54.9 & 5.0 & 52.8 & 4.9 & 0 \\
\hline \multirow[t]{2}{*}{ BMI $\left(\mathrm{kg} / \mathrm{m}^{2}\right)$} & 26.0 & 3.3 & 25.9 & 4.3 & $3(0.1)^{*}$ \\
\hline & \multicolumn{2}{|l|}{ n (\%) } & \multicolumn{2}{|l|}{ n (\%) } & \\
\hline BMI $25-29.9 \mathrm{~kg} / \mathrm{m}^{2}$ & \multicolumn{2}{|l|}{$746(51.3)$} & \multicolumn{2}{|l|}{$575(39.5)$} & $-^{*}$ \\
\hline $\mathrm{BMI} \geq 30 \mathrm{~kg} / \mathrm{m}^{2}$ & \multicolumn{2}{|l|}{$161(11.1)$} & \multicolumn{2}{|l|}{$214(14.7)$} & $-^{\star}$ \\
\hline Smoking history† & \multicolumn{2}{|l|}{$1176(80.8)$} & \multicolumn{2}{|l|}{782 (53.7) } & 0 \\
\hline All offspring $(n=2308)$ & \multicolumn{2}{|c|}{ Sons $(n=1025)$} & \multicolumn{2}{|c|}{ Daughters $(n=1283)$} & \\
\hline Age (years) & 44.8 & 6.3 & 45.2 & 6.1 & 0 \\
\hline BMI $\left(\mathrm{kg} / \mathrm{m}^{2}\right)$ & 26.5 & 4.0 & 25.9 & 5.0 & $17(0.7) \ddagger$ \\
\hline WC $(\mathrm{cm})$ & 93.5 & 10.8 & 80.1 & 12.1 & $19(0.8) \ddagger$ \\
\hline Triglycerides (mmol/L) & 1.93 & 1.51 & 1.31 & 0.80 & $80(3.5)$ \\
\hline HDL cholesterol (mmol/L) & 1.30 & 0.33 & 1.51 & 0.36 & $370(16.0)$ \\
\hline Glucose & 5.60 & 1.94 & 5.15 & 1.18 & $69(3.0)$ \\
\hline Systolic BP (mm Hg) & 131.2 & 15.3 & 123.9 & 15.6 & $25(1.1)$ \\
\hline Diastolic BP (mm Hg) & 79.1 & 11.0 & 70.9 & 10.0 & $25(1.1)$ \\
\hline \multirow[t]{2}{*}{ Birth weight $(\mathrm{kg})$} & 3.48 & 0.49 & 3.36 & 0.49 & $457(19.8)$ \\
\hline & \multicolumn{2}{|l|}{ n (\%) } & \multicolumn{2}{|l|}{ n (\%) } & \\
\hline BMI $25-29.9 \mathrm{~kg} / \mathrm{m}^{2}$ & \multicolumn{2}{|l|}{$456(44.5)$} & \multicolumn{2}{|l|}{$400(31.6)$} & $-\ddagger$ \\
\hline $\mathrm{BMI} \geq 30 \mathrm{~kg} / \mathrm{m}^{2}$ & \multicolumn{2}{|l|}{$182(17.8)$} & \multicolumn{2}{|l|}{$229(18.1)$} & $-\ddagger$ \\
\hline WC between action levels 1 and 2 (\%) & \multicolumn{2}{|l|}{$270(26.4)$} & \multicolumn{2}{|l|}{252 (19.9) } & $-\ddagger$ \\
\hline WC above action level 2 (\%) & \multicolumn{2}{|l|}{195 (19.0) } & \multicolumn{2}{|l|}{294 (23.2) } & $-\ddagger$ \\
\hline Smoking history† & \multicolumn{2}{|l|}{$575(56.1)$} & \multicolumn{2}{|l|}{$647(50.4)$} & 0 \\
\hline Angina§ & \multicolumn{2}{|l|}{$39(3.8)$} & \multicolumn{2}{|l|}{$51(4.0)$} & 0 \\
\hline Myocardial infarctๆ & \multicolumn{2}{|l|}{$38(3.7)$} & \multicolumn{2}{|l|}{$8(0.6)$} & $22(1.0)$ \\
\hline Angina and/or myocardial infarct & $73(7.1)$ & & $56(4.4)$ & & $22(1.0)$ \\
\hline Cardiac ischaemia** & $18(1.8)$ & & $25(1.9)$ & & $21(0.9)$ \\
\hline Strokes & $4(0.4)$ & & $8(0.6)$ & & 0 \\
\hline Diabetes & $13(1.3)$ & & $13(1.0)$ & & 0 \\
\hline Metabolic syndrome & $201(25.1)$ & & $173(15.4)$ & & $387(16.8)$ \\
\hline 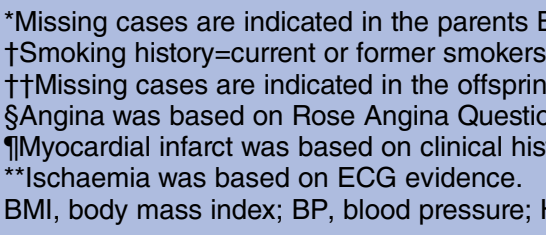 & $\begin{array}{l}\text { WC rows. } \\
\text { ECG eviden } \\
\text { density lipopI }\end{array}$ & WC & nference. & & \\
\hline
\end{tabular}

$(\beta=0.26)$ relationships. In model 2 , when further adjustments for mothers' BMI in father-offspring or fathers' BMI in mother-offspring analysis were made, there was a reduction in these regression coefficients for fatherson $(\beta=0.30)$, mother-daughter $(\beta=0.33)$, father-daughter $(\beta=0.23)$ and mother-son $(\beta=0.22)$ relationships. We

Table 2 Regression coefficients $(\beta)$ and 95\% Cls obtained from linear mixed effects model with maximum likelihood, adjusted for family clustering, parental and offspring age, smoking status and social class

\begin{tabular}{|c|c|c|c|c|c|c|}
\hline & \multicolumn{3}{|c|}{ Sons' BMI } & \multicolumn{3}{|c|}{ Daughters' BMI } \\
\hline & $\boldsymbol{\beta}$ & $\begin{array}{l}95 \% \text { Confidence } \\
\text { interval }\end{array}$ & p Value & $\boldsymbol{\beta}$ & $\begin{array}{l}95 \% \text { Confidence } \\
\text { interval }\end{array}$ & p Value \\
\hline \multicolumn{7}{|l|}{ Model 1} \\
\hline Paternal BMI & 0.35 & 0.27 to 0.42 & $<0.001$ & 0.29 & 0.21 to 0.38 & $<0.001$ \\
\hline Maternal BMI & 0.26 & 0.20 to 0.32 & $<0.001$ & 0.33 & 0.27 to 0.40 & $<0.001$ \\
\hline \multicolumn{7}{|l|}{ Model 2: additional parental BMI adjustment } \\
\hline Paternal BMI (adjusted for maternal BMI) & 0.30 & 0.23 to 0.38 & $<0.001$ & 0.23 & 0.15 to 0.32 & $<0.001$ \\
\hline Maternal BMI (adjusted for paternal BMI) & 0.22 & 0.16 to 0.28 & $<0.001$ & 0.33 & 0.24 to 0.37 & $<0.001$ \\
\hline
\end{tabular}


have also observed a significant association between the BMIs of fathers and mothers, who were assumed to not be genetically related (after adjustments for family clustering, parental age, smoking status and social class, $\beta=0.19,95 \%$ CI 0.14 to $0.25, p<0.001$ ).

Table 3 shows heritability of BMI, estimated as $\mathrm{h}_{2}$ from coefficients for offspring BMI regressed on mid-parental BMI: $\mathrm{h}^{2}$ for BMI was 0.51 in sons and 0.56 in daughters. Further analysis based on parental BMI status showed a clear pattern of $\mathrm{h}^{2}$ for BMI in offspring, with daughters having highest $\mathrm{h}^{2}$ when both parents were lean (0.99) or when at least one parent was obese $(0.76)$. For sons, $h^{2}$ was also a little above the average (0.56) with two lean parents, but lower at 0.39 for son with at least one obese parent.

Figure 1A, B shows the proportions of offspring with high WC above action level 2: $\geq 102 \mathrm{~cm}$ in males, $\geq 88 \mathrm{~cm}$ in females in different categories based on BMI of their fathers and mothers. With two lean parents, only $8.5 \%$ of sons and $14 \%$ of daughters had high WC. The rates rose proportionally with number of overweight/obese parents. There were greater proportions of high WC among sons and daughters with obese mothers $(31-33 \%)$ than with obese fathers $(22-26 \%)$. When both parents were obese, high WC was much more prevalent among both sons $(60.5 \%)$ and daughters $(71.4 \%)$. Figure $1 \mathrm{C}$, D shows similar patterns for proportions of offspring with high BMI $\geq 30 \mathrm{~kg} / \mathrm{m}^{2}$ in different categories based on BMI of their fathers and mothers.

Ever smoking was reported by $2015(87.3 \%)$ in the parents' generation, and $1222(52.9 \%)$ among the offspring. There was a history of both parents' smoking for 1098 offspring (47.6\%). Among offspring, only 131 $(10.7 \%)$ reported smoking if both parents never smoked, but $485(39.7 \%)$ if one parent had smoked and $606(49.6 \%)$ if both parents had a smoking history $\left(\chi^{2}=10.2, p=0.006\right)$. After adjustment for confounding factors family clustering, sex, offspring and parental age and social class, and parental BMI, compared with offspring whose parents never smoked, offspring with at least one parent with history of smoking had OR for becoming a smoker of 1.46 (95\% CI 1.10 to 1.93 , $\mathrm{p}=0.008)$.

Table 4 shows that after adjustment for family clustering, offspring and parental age and social class, parental BMI and offspring smoking history, increased risk of high BMI $\geq 25 \mathrm{~kg} / \mathrm{m}^{2}$ was observed in sons, but not in daughters, if fathers (OR 1.52) or similarly mothers (OR 1.46) smoked. Increased risk of high WC above action level 1 was associated with maternal smoking, both in sons (OR 1.50) and in daughters (OR 1.42), but offspring WC was not related to paternal smoking. These ORs increased further for estimating the risk of offspring for having BMI above $30 \mathrm{~kg} / \mathrm{m}^{2}$ or WC above action level 2 from parental smoking history. We did not observe any associations between maternal/parental smoking history and offspring BP, lipids, diabetes or

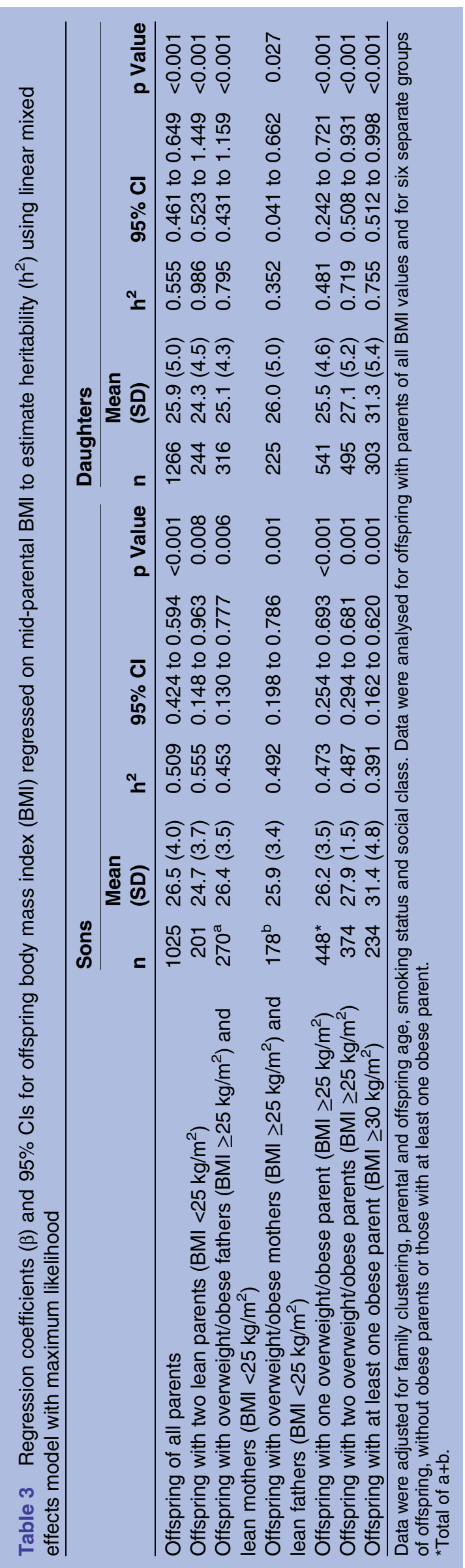



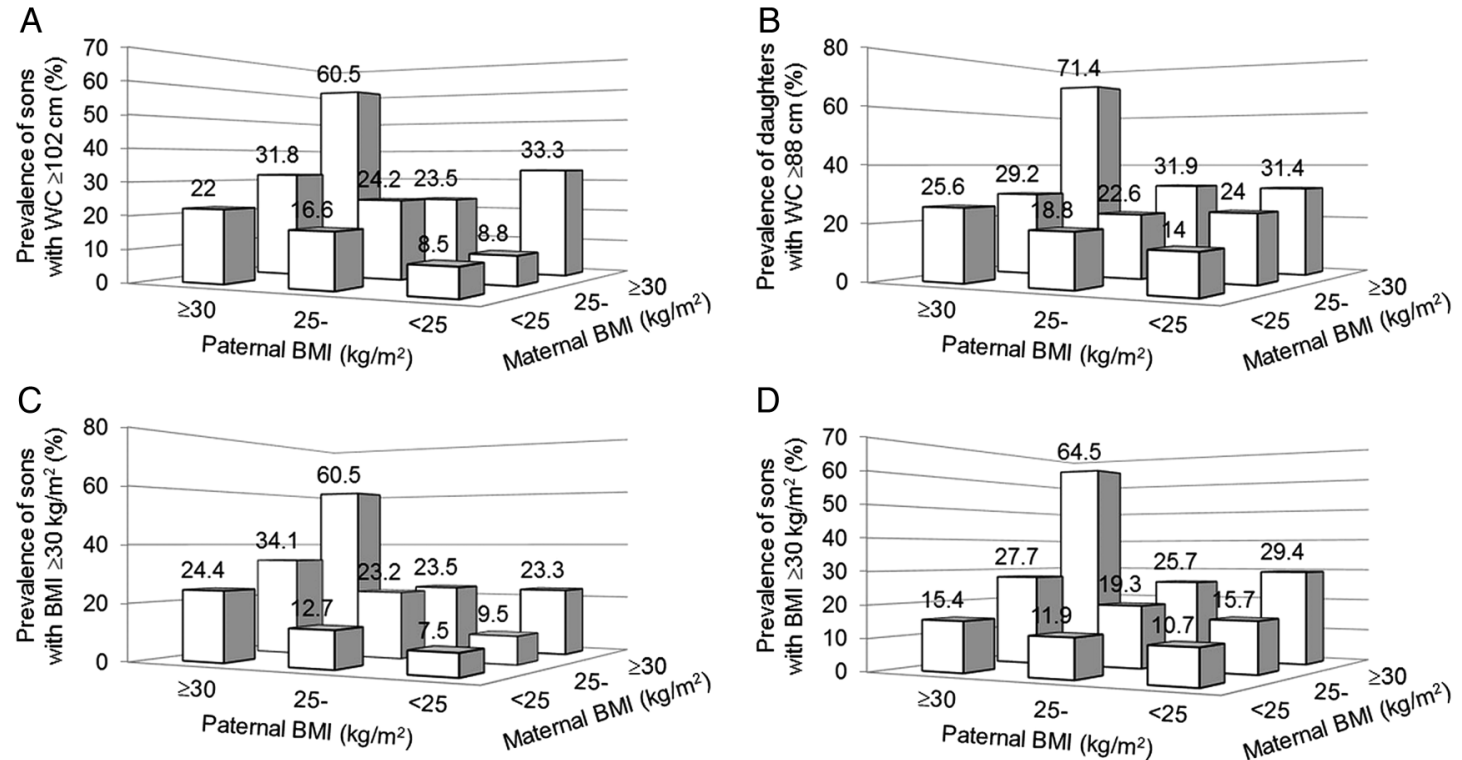

Figure 1 Proportions of offspring with high waist circumference (WC; A for sons and B for daughters) or high body mass index (BMI; C for sons and D for daughters) in different categories based on parental BMI. Offspring with large WC was proportionally more prevalent in those with overweight/obese parents.

stroke (results not shown). Maternal smoking history was associated with increased risk of metabolic syndrome in sons (OR 1.68) but not in daughters. Paternal smoking history did not associate with metabolic syndrome in offspring of either sex.

Birth weight was added to the analysis for subsets with birthweight data, showing that compared with male offspring whose birth weight was within the middle tertile (referent), those with birth weight in the highest tertitle had a 1.98-fold increase in risk of high having WC $\geq 102 \mathrm{~cm}$. There were no associations between birth weight with metabolic syndrome and cardiovascular disease. Birth weight somewhat diminished the relationships between parental smoking and WC above action level 2 or BMI above $30 \mathrm{~kg} / \mathrm{m}^{2}$ while accentuating the relationships between parental smoking and WC above action level 1, BMI above $25 \mathrm{~kg} / \mathrm{m}^{2}$ or metabolic syndrome. There were no associations between offspring in the lowest tertile of birth weight and increased health risk (obesity, metabolic syndrome or cardiovascular disease).

Table 5 shows that, compared with offspring with nonobese parents $\left(\mathrm{BMI}<30 \mathrm{~kg} / \mathrm{m}^{2}\right.$ ), the risk for offspring of having a high waist was twofold greater in those with one obese parent. With two obese parents, this risk to offspring rose to 7-fold for having WC above action level 1 and 10-fold for having WC above action level 2. Offspring with two obese parents also had increased risk of having metabolic syndrome (OR 2.46). These results included adjustments for sex, offspring and parental age, smoking status and social class. Similar risks among offspring with obese parents were observed for having high BMI.

Compared with offspring with no obese parents, offspring with two obese parents had adjusted ORs of 3-5 for having angina and/or myocardial infarct. These ORs fell to between 2 and 3 if the analysis was adjusted for BMI of offspring.

We found no differences in prevalences of individual cardiometabolic risk factors between groups of offspring categorised according to their parents' levels of BMI: lean, overweight or obese (data not presented).

Among the offspring there were 12 who reported strokes, 26 with diabetes and 21 with cardiac ischaemia on ECG. Parental adiposity (based on BMI categories) was not associated with risk of offspring stroke, diabetes mellitus or ischaemia (data not presented).

\section{DISCUSSION}

\section{Summary of key results}

This study has demonstrated relationships between the BMI, and smoking habits, of parents on the weight status and cardiovascular risk of their offspring in early middle age. Offspring birth weight had little influences on these health outcomes in adult life. These relationships proved to be robust after adjustment for potential confounders such as age, socioeconomic status and offspring smoking. The influences from mothers' smoking history tend to be stronger than those from fathers, which can be interpreted to suggest possible epigenetic mechanisms worthy of future exploration.

\section{Association between parental adiposity and offspring adiposity}

This study has valuably strengthened our understanding of the genetic-environmental influences on obesity, by assessing weight status of offspring when they are middle-aged, when adiposity status is well established. 
Table 4 Generalised estimating equations to estimate ORs of the risk of offspring with parental history of smoking for having high waist circumference (WC; above action level 1 or above action level 2), high body mass index (BMl; $\geq 25$ or $\geq 30 \mathrm{~kg} / \mathrm{m}^{2}$ )

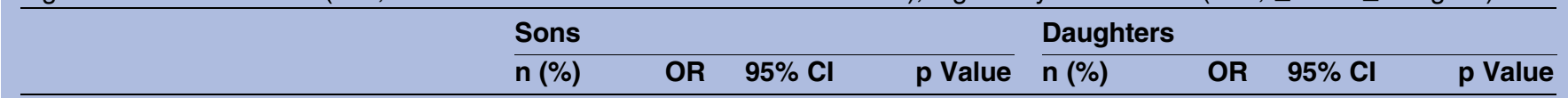

Model 1: risk of WC above action level 1

Paternal smoking history*

Maternal smoking history*

$829(80.9) \quad 1.21 \quad 0.84$ to $1.75 \quad 0.307$

$555(54.1) \quad 1.50 \quad 1.13$ to $2.01 \quad 0.006$

$892(87.0) \quad 1.76 \quad 1.15$ to $2.70 \quad 0.010$ history

Model 2: risk of WC above action level 1 (additional birthweight variable)

Paternal smoking history*

Maternal smoking history*

$640(80.7) \quad 1.20 \quad 0.80$ to $1.81 \quad 0.378$

$428(54.0) \quad 1.56 \quad 1.13$ to $2.16 \quad 0.008$

$684(86.3) \quad 1.97 \quad 1.21$ to $3.20 \quad 0.007$

At least one parent with smoking

history

High birth weight (highest tertile) $\dagger \quad 248$ (31.3) $\quad 1.21 \quad 0.82$ to $1.78 \quad 0.347$

Model 1: risk of WC above action level 2

Paternal smoking history*

Maternal smoking history*

$\begin{array}{llll}829(80.9) & 1.09 & 0.70 \text { to } 1.70 & 0.697\end{array}$

$\begin{array}{llll}555(54.1) & 1.67 & 1.14 \text { to } 2.45 & 0.009\end{array}$

At least one parent with smoking

$892(87.0) \quad 1.54 \quad 0.94$ to $2.52 \quad 0.086$ history

Model 2: risk of WC above action level 2 (additional birthweight variable)

Paternal smoking history*

Maternal smoking history*

$\begin{array}{llll}640(80.7) & 1.11 & 0.66 \text { to } 1.85 & 0.703\end{array}$

$\begin{array}{llll}428(54.0) & 1.53 & 0.98 \text { to } 2.38 & 0.060\end{array}$

At least one parent with smoking

history

High birth weight (highest tertile) $\dagger$

Model 1: risk of BMl above $25 \mathrm{~kg} / \mathrm{m}^{2}$

Paternal smoking history*

Maternal smoking history*

At least one parent with smoking history

Model 2: risk of BMl above $25 \mathrm{~kg} / \mathrm{m}^{2}$ (additional birthweight variable)

Paternal smoking history*

Maternal smoking history*

At least one parent with smoking

history

High birth weight (highest tertile) $\dagger$

Model 1: risk of BMI above $30 \mathrm{~kg} / \mathrm{m}^{2}$

Paternal smoking history*

Maternal smoking history*

At least one parent with smoking

history

Model 2: risk of BMl above $30 \mathrm{~kg} / \mathrm{m}^{2}$

Paternal smoking history*

Maternal smoking history

At least one parent with smoking

history

High birth weight (highest tertile) $\dagger$

Model 1: risk of metabolic syndrome‡

Paternal smoking history ${ }^{*}$

Maternal smoking history*

At least one parent with smoking

history

Model 2: risk of metabolic syndrome (additional birthweight variable)‡

Paternal smoking history*

Maternal smoking history*

$684(86.3) \quad 1.35 \quad 0.78$ to $2.34 \quad 0.288$

$248(31.3) \quad 1.98 \quad 1.23$ to $3.20 \quad 0.005$

$829(80.9) \quad 1.52 \quad 1.05$ to $2.20 \quad 0.025$

$\begin{array}{llll}555(54.1) & 1.46 & 1.09 \text { to } 1.97 & 0.013\end{array}$

$892(87.0) \quad 2.01 \quad 1.33$ to $3.03 \quad 0.001$

$640(80.7) \quad 1.51 \quad 1.01$ to $2.27 \quad 0.046$

$428(54.0) \quad 1.60 \quad 1.15$ to $2.24 \quad 0.006$

684 (86.3) $2.21 \quad 1.39$ to $3.52 \quad 0.001$

$248(31.3) \quad 1.28 \quad 0.86$ to $1.91 \quad 0.226$

$829(80.9) \quad 1.54 \quad 0.93$ to $2.53 \quad 0.091$

$555(54.1) \quad 1.79 \quad 1.23$ to $2.62 \quad 0.003$

$892(87.0) \quad 1.95 \quad 1.10$ to $3.44 \quad 0.022$

$829(80.9) \quad 1.66 \quad 0.93$ to $3.00 \quad 0.089$

$\begin{array}{llll}555(54.1) & 1.71 & 1.11 \text { to } 2.62 & 0.014\end{array}$

$\begin{array}{llll}892(87.0) & 1.82 & 0.95 \text { to } 3.48 & 0.072\end{array}$

248 (31.3) $1.64 \quad 0.98$ to $2.72 \quad 0.058$

$\begin{array}{lllll}646(80.6) & 1.12 & 0.73 \text { to } 1.73 & 0.669\end{array}$

$\begin{array}{llll}433(54.1) & 1.68 & 1.17 \text { to } 2.40 & 0.005\end{array}$

$\begin{array}{llll}692(86.4) & 1.72 & 1.01 \text { to } 2.94 & 0.047\end{array}$

$496(80.1) \quad 1.00 \quad 0.65$ to $1.54 \quad 0.995$

$\begin{array}{lllll}330 & (53.3) & 1.83 & 1.28 \text { to } 2.64 & 0.001\end{array}$

$\begin{array}{lllll}528 & (85.3) & 1.81 & 1.07 \text { to } 3.07 & 0.027\end{array}$
1035 (80.7) $\quad 1.02 \quad 0.74$ to $1.42 \quad 0.894$

$\begin{array}{llll}694(54.1) & 1.42 & 1.10 \text { to } 1.84 & 0.007\end{array}$

$1123(87.5) \quad 1.42 \quad 0.98$ to $2.00 \quad 0.061$

848 (80.2) $\quad 1.13 \quad 0.79$ to $1.62 \quad 0.510$

$\begin{array}{llll}580(54.8) & 1.40 & 1.06 \text { to } 1.85 & 0.018\end{array}$

927 (87.6) $\quad 1.66 \quad 1.10$ to $2.51 \quad 0.017$

359 (33.9) $\quad 1.06 \quad 0.77$ to $1.46 \quad 0.720$

$1035(80.7) \quad 1.10 \quad 0.73$ to $1.66 \quad 0.642$

$\begin{array}{lllll}694(54.1) & 1.38 & 1.02 \text { to } 1.87 & 0.036\end{array}$

$1123(87.5) \quad 1.52 \quad 0.91$ to $2.53 \quad 0.107$

$\begin{array}{llll}848(80.2) & 1.04 & 0.70 \text { to } 1.33 & 0.821\end{array}$

$\begin{array}{llll}580(54.8) & 1.30 & 0.93 \text { to } 1.81 & 0.306\end{array}$

$927(87.6) \quad 1.48 \quad 0.85$ to $2.58 \quad 0.166$

359 (33.9) $\quad 1.36 \quad 0.92$ to $2.00 \quad 0.121$

1035 (80.7) $\quad 1.22 \quad 0.87$ to $1.70 \quad 0.244$

$\begin{array}{lllll}694(54.1) & 1.13 & 0.88 \text { to } 1.46 & 0.335\end{array}$

$\begin{array}{llll}1123(87.5) & 1.43 & 0.98 \text { to } 2.10 & 0.067\end{array}$

1035 (80.7) $\quad 1.29 \quad 0.90$ to $1.85 \quad 0.172$

694 (54.1) $\quad 1.01 \quad 0.77$ to $1.33 \quad 0.932$

$1123(87.5) \quad 1.39 \quad 0.92$ to $2.09 \quad 0.118$

359 (33.9) $\quad 1.13 \quad 0.82$ to $1.56 \quad 0.447$

$\begin{array}{lllll}1035(80.7) & 1.14 & 0.73 \text { to } 1.77 & 0.577\end{array}$

$\begin{array}{lllll}694(54.1) & 1.25 & 0.89 & \text { to } 1.74 & 0.193\end{array}$

$1123(87.5) \quad 1.45 \quad 0.85$ to $2.49 \quad 0.176$

1035 (80.7) $\quad 1.08 \quad 0.66$ to $1.77 \quad 0.761$

$\begin{array}{llll}694(54.1) & 1.18 & 0.81 \text { to } 1.71 & 0.383\end{array}$

$1123(87.5) \quad 1.49 \quad 0.80$ to $2.76 \quad 0.205$

359 (33.9) $\quad 1.25 \quad 0.83$ to $1.89 \quad 0.295$

$\begin{array}{lllll}910(81.3) & 0.87 & 0.56 \text { to } 1.36 & 0.544\end{array}$ $\begin{array}{llll}602(53.8) & 1.18 & 0.81 \text { to } 1.71 & 0.387\end{array}$

$\begin{array}{lllll}979(87.4) & 0.92 & 0.56 \text { to } 1.51 & 0.727\end{array}$

$746(80.6) \quad 1.00 \quad 0.63$ to $1.60 \quad 0.981$

$\begin{array}{llll}505(54.5) & 1.14 & 0.77 \text { to } 1.69 & 0.506\end{array}$

808 (87.3) $\quad 1.24 \quad 0.70$ to $2.19 \quad 0.456$ history

High birth weight (highest tertile) $\dagger$

$196(31.7) \quad 1.30 \quad 0.88$ to $1.93 \quad 0.189$

$322(34.8) \quad 0.97 \quad 0.64$ to $1.60 \quad 0.884$

Data were adjusted for offspring and parental age, social class, parental BMI, and offspring smoking history (model 1) and additional birthweight adjustment (model 2).

*Variables were entered in regression simultaneously.

†Reference group: second birthweight tertile.

$\ddagger$ There were 1921 cases with complete data for constructing metabolic syndrome. 
Table 5 Generalised estimating equations to estimate ORs of the risk of offspring for having high waist circumference (WC; above action level 1 or above action level 2), high body mass index (BMl; $\geq 25$ or $\geq 30 \mathrm{~kg} / \mathrm{m}^{2}$ ), angina (Rose Angina Questionnaire) and myocardial infarct (self-reported or ECG evidence)

\begin{tabular}{|c|c|c|c|c|c|c|c|c|c|c|}
\hline & \multicolumn{2}{|c|}{$\begin{array}{l}\text { Two non-obese } \\
\text { parents (referent) } \\
\mathrm{n}=1766(76.5 \%) \\
\end{array}$} & \multicolumn{4}{|c|}{$\begin{array}{l}\text { One obese parent } \\
n=464(20.3 \%)\end{array}$} & \multicolumn{4}{|c|}{$\begin{array}{l}\text { Two obese parents } \\
n=73(3.2 \%)\end{array}$} \\
\hline & Per cent & OR & $\begin{array}{l}\text { Per } \\
\text { cent }\end{array}$ & OR & $95 \% \mathrm{Cl}$ & p Value & $\begin{array}{l}\text { Per } \\
\text { cent }\end{array}$ & OR & $95 \% \mathrm{Cl}$ & p Value \\
\hline \multicolumn{11}{|l|}{ Model 1} \\
\hline WC above action level 1 & 40.0 & 1 & 54.1 & 1.84 & 1.46 to 2.33 & $<0.001$ & 80.8 & 6.84 & 3.70 to 12.65 & $<0.001$ \\
\hline WC above action level 2 & 17.6 & 1 & 28.7 & 1.90 & 1.46 to 2.46 & $<0.001$ & 65.8 & 10.25 & 6.56 to 13.93 & $<0.001$ \\
\hline $\mathrm{BMI} \geq 25 \mathrm{~kg} / \mathrm{m}^{2}$ & 50.7 & 1 & 67.0 & 1.96 & 1.54 to 2.48 & $<0.001$ & 91.8 & 10.40 & 4.65 to 13.29 & $<0.001$ \\
\hline $\mathrm{BMI} \geq 30 \mathrm{~kg} / \mathrm{m}^{2}$ & 14.0 & 1 & 25.6 & 2.14 & 1.62 to 2.81 & $<0.001$ & 63.0 & 11.77 & 7.70 to 18.00 & $<0.001$ \\
\hline Metabolic syndrome* & 18.5 & 1 & 21.2 & 1.18 & 0.86 to 1.62 & 0.311 & 34.5 & 2.46 & 1.33 to 4.57 & 0.004 \\
\hline Angina & 3.7 & 1 & 3.4 & 0.86 & 0.48 to 1.54 & 0.614 & 11.0 & 2.74 & 1.27 to 5.92 & 0.010 \\
\hline Myocardial infarct & 1.7 & 1 & 1.7 & 0.92 & 0.42 to 2.00 & 0.828 & 11.1 & 5.53 & 2.53 to 12.07 & $<0.001$ \\
\hline $\begin{array}{l}\text { Angina and/or } \\
\text { myocardial infarct }\end{array}$ & 5.2 & 1 & 5.0 & 0.89 & 0.55 to 1.43 & 0.619 & 20.8 & 4.14 & 2.15 to 8.00 & $<0.001$ \\
\hline \multicolumn{11}{|c|}{ Model 2 (additional offspring BMI adjustment) } \\
\hline Angina & 3.7 & 1 & 3.4 & 0.80 & 0.45 to 1.44 & 0.462 & 11.0 & 2.08 & 0.95 to 4.58 & 0.068 \\
\hline Myocardial infarct & 1.7 & 1 & 1.7 & 0.75 & 0.34 to 1.63 & 0.464 & 11.1 & 3.26 & 1.43 to 7.43 & 0.005 \\
\hline $\begin{array}{l}\text { Angina and/or } \\
\text { myocardial infarct }\end{array}$ & 5.2 & 1 & 5.0 & 0.81 & 0.50 to 1.32 & 0.401 & 20.8 & 3.03 & 1.55 to 5.91 & 0.001 \\
\hline
\end{tabular}

This is important as most of the weight gain leading to obesity occurs in early adulthood: while only $12 \%$ of males and $20 \%$ of females have BMI $>30 \mathrm{~kg} / \mathrm{m}^{2}$ when aged 16-24 years almost $40 \%$ of all UK adults become obese by late middle age. ${ }^{36}$ Studying offspring at younger ages cannot reliably identify those who will ultimately become obese.

The results in this Caucasian, European population show that although the BMI relationships between parents and adult offspring are statistically significant, the effect sizes relating parental to offspring BMI are relatively small ( $\beta$ range $0.22-0.33$ ), and only slightly greater in size than the BMI association between their non-genetically related fathers and mothers $\left(\begin{array}{ll}\beta & 0.19\end{array}\right)$. We have previously published data on parental-offspring BMI relationships showing coefficient values to be lower than those observed in the present study. ${ }^{26}$ These discrepancies were due to differences in selection of confounding factors and method of analysis-the study by Johnson et $a l^{26}$ included marital status and number of children as confounding factors as well as $\log$ of BMI and used linear regression models. Analysis in the present study adjusted for family clustering, social class and smoking status for both generations using linear mixed effects model. Despite these differences, the patterns of parental-offspring associations remained similar for both studies in that same sex associations (father-son, mother-daughter) were stronger than opposite sex associations.

Previous studies on familial obesity tended to focus on the mother-daughter relationship, with fewer published data on father-son relationships, especially among adult offspring. Linabery $e t a l^{22}$ found that maternal BMI had a stronger influence on BMI growth of infants aged 1.53.5 years than paternal BMI and similarly Gaillard et $a 2^{20}$ found that childhood overweight was more influenced by maternal obesity than paternal obesity. Gaillard $e t a t^{20}$ suggested direct intrauterine mechanisms as an explanation for this parental difference. Perez-Pastor et $a i^{88}$ found that girls with obese mothers and boys with obese fathers were more likely to have high BMI in childhood. The much weaker relationship between BMIs of mothers and sons, or fathers and daughters, led the authors to conclude that behaviour, rather than genetics, was the dominant factor determining childhood obesity. Fleten et $a l^{19}$ compared the maternal-offspring BMI association with the paternal-offspring BMI association when the offspring were 3 years old also concluded that maternal-offspring association may be explained by shared familial risk factors rather than by the intrauterine environment. Findings from our study in adult offspring are consistent with those from studies of children, ${ }^{25}$ showing that both paternal and maternal BMI had significant influences on BMI of sons or daughters. Our study found that maternal BMI had marginally greater impact on daughters than paternal BMI on sons. Our findings of BMI and prevalence of obesity of offspring being higher than that of their parents are consistent with previous studies. ${ }^{23}$ The observation that maternal BMI was more strongly associated with offspring birth weight than was paternal BMI, but no 
differences in parent-offspring associations for BMI when offspring were between 3 and 39 years led Kivimäki $e t a l^{23}$ to conclude that higher adult BMI for offspring than for parents is likely explained by environmental influences. Our study found that the parental influence on adiposity was far greater when two parents were obese, but the father-daughter and mother-son influences on BMI were much weaker than with like-sex offspring.

\section{Heritability, genetics and epigenetics of obesity}

Heritability estimates were generally higher for daughters than for sons, with highest values in women when their mother's BMI values were either below 25 or above $30 \mathrm{~kg} / \mathrm{m}^{2}$. For both sexes, heritability was higher among offspring with thinner parents than among those with fatter parents. Our results support the general conclusion from other studies, that genetic contributions to obesity are rather less than environmental ones, ${ }^{39}$ and that the high heritability of obesity, especially documented among twins is more to do with shared environmental factors. ${ }^{40}$ In line with studies among children, ${ }^{39}$ the present study has shown that intergenerational relationships of BMI were strongest between mothers and daughters and between fathers and sons, which may point to epigenetic effects. ${ }^{41}$ Conventional genetics does not appear to provide full explanations for obesity. The most powerful common single-gene influences on human obesity, for example, $F T O$, have only small effects on BMI, increasing risk of obesity by 1.2 -fold. ${ }^{42}$ Since obesity is a polygenic disorder, individuals who carry many variants (more than 10) are more susceptible to gaining weight than those who carry only one or two variants. ${ }^{43}$ Although obesity clearly has some genetic aetiology, ${ }^{58}$ its manifestation always requires an interaction with adverse environmental factors to upset energy balance during weight gain, and to permit weight maintenance at a high level. Elks et $a t^{44}$ reviewed and performed metaregression of 88 twin studies and 27 family studies and found that BMI heritability estimates were highly variable and were generally higher from twin studies $(0.47-0.90)$ than family studies $(0.24-0.81)$. Our family study found $\mathrm{h}^{2}$ for BMI to be within this range $(0.51$ in men to 0.56 in women). We saw a clear contrast in $\mathrm{h}^{2}$ for BMI between women and men, when there were two lean parents $\left(\mathrm{h}^{2}=0.99\right.$ in women and 0.56 in men) and also when there was at least one obese parent $\left(\mathrm{h}^{2}=0.76\right.$ in women and 0.39 in men). It should be emphasised that $\mathrm{h}^{2}$ estimate for BMI represents not only parents' and offspring's share of half of their genome but also many common environmental factors that are transmitted to the next generation. The association between BMIs of fathers and mothers who are not genetically related suggests that a substantial part of the association between parental BMI and offspring BMI were due to non-genetic familial influences, reflecting shared habits and environments which are likely to be passed on to offspring as well. Further evidence to support the implications that adverse lifestyles shared by family members that contribute to obesity arises from the observation of greater risk of offspring obesity from parental smoking history and low social class. Undoubtedly, family traditions of poor diet quality and physical inactivity would play major roles in familial obesity. We did not have data to analyse these aspects, but the very different influences from maternal and paternal smoking weigh against purely social mechanisms. It has been suggested by others that 'missing heritability', not fully accounted for by conventional genetics, may be explained by epigenetic mechanisms. ${ }^{9}$ The original Renfrew \& Paisley Study database did not include information about smoking of their parents (ie, grandparents of the Midspan offspring). It was therefore not possible to adjust the estimates of $\mathrm{h}^{2}$ for parental smoking in both generations.

\section{Parental smoking and offspring adiposity}

A number of studies have indicated parental smoking as risk of obesity in offspring. Studies of women aged $17-47^{15}$ and $13-28$ years found that daughters of mothers who smoked during pregnancy had increased the risk of obesity.

Our observation of increased risk of high WC in adult offspring whose mothers smoked is novel and consistent with recent studies of more than 5000 adolescents aged 10-18 years which showed that prenatal maternal exposure to smoking, including passive smoke was associated with increased risk of obesity in adolescents, independent of birth weight. ${ }^{45}$ Similar evidence arise from other studies showing that either parent ${ }^{17}$ or mothers who smoked $^{18}$ during pregnancy was associated with an increase in WC and BMI of offspring at $32^{17}$ and 45 years old. ${ }^{18}$

Although this effect may point to potential epigenetic mechanisms, with a study of only two generations, it is not possible to distinguish between what is sometimes termed 'multigenerational' and 'transgenerational' transmission of an acquired trait in animal models. ${ }^{46}$ Maternal smoking is also associated with shorter offspring. ${ }^{47}$ It is unlikely that height has significant influences on the relationship between maternal smoking and offspring adiposity since height only explained $2 \%$ of the variance in WC in male and $0 \%$ in female offspring, and $0 \%$ of the variance in BMI in male and $1 \%$ in female offspring. In our study, after adjustments for parental and offspring age and social class and parental BMI, maternal smoking had significant effects on sons' and daughters' WC, but paternal smoking had no effect. When at least one of the parents smoked, the risk of high BMI was increased in sons indicating interaction or additive effect of both parents' smoking history. This effect was not observed in daughters. The lack of a similar effect on WC from fathers who smoked could again point towards an epigenetic effect on increased adult central fat distribution, mediated by exposure to 
exogenous free radicals in pregnancy resulted in changes such as DNA methylation. ${ }^{48}$ This hypothesis would be consistent in general terms with the programming hypothesis of early uterine environment, whereby stress at critical stages of pregnancy resulted in the later adverse health consequences of metabolic syndrome. ${ }^{8}$ We found no significant associations between parental smoking history and individual features of metabolic syndrome in offspring, although parental obesity was associated with high WC and coronary heart disease in their offspring. However, we have found that maternal smoking history was significantly associated with increased risk of metabolic syndrome in sons.

\section{Influences of offspring birth weight on offspring adiposity and health outcomes}

It has been observed that the genetic contributions are more evident for obesity manifesting in early childhood than adult life. ${ }^{44}$ Gestational weight gain is related to increased offspring BMI in childhood, ${ }^{49}$ adolescence ${ }^{50}$ and young adults. ${ }^{51}$ Fraser et $a \tilde{l}^{22}$ analysed over 5000 mother-offspring pairs from a UK prospective pregnancy cohort and found that greater maternal prepregnancy weight and gestational weight gain were associated with greater offspring adiposity and adverse cardiovascular risk factors at 9 years of age. These findings have suggested epigenetic programming of early-onset offspring obesity. ${ }^{53}$

A previous study of women has shown an inverse relationship between birth weight and intra-abdominal fat measured by MRI. ${ }^{7}$ Evidence from our study of offspring birth weight associating only with increased risk of high WC in male adult life does not add support to the general programming hypothesis of Barker. ${ }^{8}$ However, the relationship between birth weight and adult health is complex since abnormal birth weight may mark a range of environmental insults to the fetus. Birth weight does not reflect the complete picture of body morphology such as body lengths or circumferences.

\section{Parental adiposity and cardiovascular disease}

We found a relationship between parental obesity and offspring angina and myocardial infarct (MI), which was largely explained by relationships between parental obesity with offspring smoking habits and adiposity (either by BMI or WC). However, this relationship remained significant after adjustments for a number of confounding factors that are known to affect BMI including offspring and parental age, smoking history, social class and offspring BMI. This remaining relationship suggests possible underlying genetic/epigenetic factors linking parental obesity and offspring's risk of heart disease. Various criteria for MI, either on the basis of clinical history, ECG evidence or both, were analysed in the present study, all of which showed similar outcomes in relation to parental adiposity. We have also observed significantly greater risk of metabolic syndrome in offspring with two obese parents.

\section{Strengths and limitations}

Our study included a large number of well-characterised participants in a stable population, with high response rates $(>70 \%)$. Its design allowed, unusually and importantly, outcome analysis among offspring as adults, with relevant data for analysis of familial obesity and related diseases and risk factors. To interpret the results, we were able to adjust our data for major confounders, but the possibility of residual confounding always exists in hypothesis-generating research of this kind, so confirmation in future research would be welcomed. It is important to recognise that this study was restricted to a Caucasian population under prevailing conditions stretching back 50-70 years, so caution must be exercised in generalising the results. Bias might have been introduced from outcome measures which were recalled or self-reported and from the lack of information of physical activity. Data were not available to assess maternal smoking specifically during pregnancy. Some mothers may have discontinued smoking during pregnancy which could underestimate our findings, but there was little advice or pressure on women to discontinue smoking in pregnancy at the time of data collection, so most probably continued. Passive smoking (largely from fathers) was also likely to persist during pregnancy. It is possible that for mothers who abstained from smoking during pregnancy, their placental and fetal development could still endure from chronic effects of smoking. We do not have direct evidence for this but this area of study deserves further investigations. On the other hand, it is possible that early childhood contact may be closer with the mothers than fathers could influence offspring behaviours including dietary, smoking and physical activity habits that result in adult obesity.

We assumed that all offspring were biologically related to both parents in the present study and that the parents were not related to one another. Parental differences in the association with their offspring's BMI could be due to non-paternity leading to weaker paternal-offspring BMI relationship than that of maternal-offspring BMI relationship. There are no specific data from which to estimate the rate of nonbiological fathers, so we assume non-paternity in this study would be similar to those in the UK at the time (between 2 and $15 \%) .{ }^{54}$

At the time of questionnaire completion, the ages of offspring (mean 45, SD 6 years) meant that prevalence of cardiovascular disease was still relatively low, particularly in women, so conclusions can only be drawn for early-onset CHD, and true associations with CHD may still exist. In the present study, $\mathrm{h}^{2}$ was estimated from regression coefficients derived from linear mixed model by regressing mid-parental BMI on offspring BMI as suggested by Visscher et al. ${ }^{34}$ This technique has certain limitations and seems to overestimate $h^{2}$ as observed in some of the values approaching 1 due to high correlations between parental and offspring BMI and when the sample size is small in subgroup analysis. ${ }^{55}$ 


\section{CONCLUSIONS}

Evidence from our study supports the existence of genetic/epigenetic-environmental interaction in the genesis of obesity and coronary heart disease, but points to a dominant environmental influence with rather limited genetic influences, most marked between mothers and daughters, fathers and sons. A possible epigenetic mechanism linking maternal smoking to obesity and metabolic syndrome in offspring is proposed. Given that most obese adults have gained weight during adulthood, individuals with family histories of obesity should be targeted from an early age to prevent obesity and complications.

\section{Author affiliations}

${ }^{1}$ Institute of Cardiovascular Research, Royal Holloway University of London (ICR2UL) \& Ashford and St Peter's NHS Foundation Trust, Surrey, UK ${ }^{2}$ Institute of Health and Wellbeing, University of Glasgow, Glasgow, UK ${ }^{3}$ Robertson Centre for Biostatics, University of Glasgow, Glasgow, UK ${ }^{4} \mathrm{BHF}$ Cardiovascular Research Centre, University of Glasgow, Glasgow, UK ${ }^{5}$ Woodlands Family Medical Centre, Stockton-on-Tees, UK

${ }^{6}$ School of Medicine, Royal Infirmary, University of Glasgow, Glasgow, UK

Acknowledgements The authors are very grateful to the Midspan Steering Committee for permission to use Midspan data.

Contributors TSH and MEJL articulated the conceptual framework and wrote the first draft. TSH developed the analytical approach and analysed the data. TSH, CLH, CH, JL, MNU, GCMW and MEJL contributed to the final study design, interpretation of data and added intellectual content during manuscript preparation. All authors read and approved the final manuscript. TSH and MEJL are the guarantors for the study.

Funding This research received no specific grant from any funding agency in the public, commercial or not-for-profit sectors.

\section{Competing interests None declared.}

Ethics approval Local Research Ethics Committee of relevant Health Boards.

Provenance and peer review Not commissioned; externally peer reviewed.

Data sharing statement No additional data are available.

Open Access This is an Open Access article distributed in accordance with the Creative Commons Attribution Non Commercial (CC BY-NC 4.0) license, which permits others to distribute, remix, adapt, build upon this work noncommercially, and license their derivative works on different terms, provided the original work is properly cited and the use is non-commercial. See: http:// creativecommons.org/licenses/by-nc/4.0/

\section{REFERENCES}

1. von Lengerke $T$, Krauth $C$. Economic costs of adult obesity: a review of recent European studies with a focus on subgroup-specific costs. Maturitas 2011;69:220-9.

2. Tigbe WW, Briggs AH, Lean ME. A patient-centred approach to estimate total annual healthcare cost by body mass index in the UK Counterweight programme. Int J Obes 2012;37:1135-9.

3. Lean ME, Han TS, Seidell JC. Impairment of health and quality of life in people with large waist circumference. Lancet 1998;351:853-6.

4. Janssen I, Katzmarzyk PT, Ross R. Body mass index, waist circumference, and health risk: evidence in support of current National Institutes of Health guidelines. Arch Intern Med 2002;162:2074-9.

5. Stunkard AJ, Harris JR, Pedersen NL, et al. The body-mass index of twins who have been reared apart. N Engl J Med 1990;322:1483-7.

6. O'Rahilly S, Farooqi IS. Human obesity: a heritable neurobehavioral disorder that is highly sensitive to environmental conditions. Diabetes 2008;57:2905-10.
7. Han TS, McNeill G, Campbell DM. The relationship between women's birth weight and their current intra-abdominal fat-mass. Proc Nutr Soc 1995;54:182A.

8. Barker DJ. Fetal and infant origins of adult disease. BMJ 1990;301:1111.

9. Youngson NA, Morris MJ. What obesity research tells us about epigenetic mechanisms. Philos Trans R Soc Lond B Biol Sci 2013;368:20110337.

10. Alberti KG, Eckel RH, Grundy SM, et al. Harmonizing the metabolic syndrome: a joint interim statement of the International Diabetes Federation Task Force on Epidemiology and Prevention; National Heart, Lung, and Blood Institute; American Heart Association; World Heart Federation; International Atherosclerosis Society; and International Association for the Study of Obesity. Circulation 2009;120:1640-5.

11. Expert Panel on Detection Evaluation, and Treatment of High Blood Cholesterol in Adults. Executive Summary of the third report of the National Cholesterol Education Program (NCEP) Expert Panel on detection, evaluation, and treatment of high blood cholesterol in adults (Adult Treatment Panel III). JAMA 2001;285:2486-97.

12. Ford ES. Risks for all-cause mortality, cardiovascular disease, and diabetes associated with the metabolic syndrome: a summary of the evidence. Diabetes Care 2005;28:1769-78.

13. Mottillo S, Filion KB, Genest J, et al. The metabolic syndrome and cardiovascular risk a systematic review and meta-analysis. J Am Coll Cardiol 2010;56:1113-32.

14. Sun K, Liu J, Ning G. Active smoking and risk of metabolic syndrome: a meta-analysis of prospective studies. PLOS ONE 2012;7:e47791.

15. Cupul-Uicab LA, Skjaerven R, Haug K, et al. In utero exposure to maternal tobacco smoke and subsequent obesity, hypertension, and gestational diabetes among women in the MoBa cohort. Environ Health Perspect 2012;120:355-60.

16. Mattsson K, Källén K, Longnecker MP, et al. Maternal smoking during pregnancy and daughters' risk of gestational diabetes and obesity. Diabetologia 2013;56:1689-95.

17. Dior UP, Lawrence GM, Sitlani C, et al. Parental smoking during pregnancy and offspring cardio-metabolic risk factors at ages 17 and 32. Atherosclerosis 2014;235:430-7.

18. Power $\mathrm{C}$, Atherton $\mathrm{K}$, Thomas $\mathrm{C}$. Maternal smoking in pregnancy, adult adiposity and other risk factors for cardiovascular disease. Atherosclerosis 2010;211:643-8.

19. Fleten $\mathrm{C}$, Nystad $\mathrm{W}$, Stigum $\mathrm{H}$, et al. Parent-offspring body mass index associations in the Norwegian Mother and Child Cohort Study: a family-based approach to studying the role of the intrauterine environment in childhood adiposity. Am J Epidemiol 2012;176:83-92.

20. Gaillard R, Felix JF, Duijts L, et al. Childhood consequences of maternal obesity and excessive weight gain during pregnancy. Acta Obstet Gynecol Scand 2014;93:1085-9.

21. Patro B, Liber A, Zalewski B, et al. Maternal and paternal body mass index and offspring obesity: a systematic review. Ann Nutr Metab 2013;63:32-41.

22. Linabery AM, Nahhas RW, Johnson W, et al. Stronger influence of maternal than paternal obesity on infant and early childhood body mass index: the Fels Longitudinal Study. Pediatr Obes 2013;8:159-69.

23. Kivimäki M, Lawlor DA, Smith GD, et al. Substantia intergenerational increases in body mass index are not explained by the fetal overnutrition hypothesis: the Cardiovascular Risk in Young Finns Study. Am J Clin Nutr 2007;86:1509-14.

24. Chaparro MP, Koupil I. The impact of parental educational trajectories on their adult offspring's overweight/obesity status: a study of three generations of Swedish men and women. Soc Sci Med 2014;120:199-207.

25. Abu-Rmeileh NM, Hart CL, McConnachie A, et al. Contribution of midparental BMI and other determinants of obesity in adult offspring. Obesity (Silver Spring) 2008;16:1388-93.

26. Johnson PC, Logue J, McConnachie A, et al. Intergenerational change and familial aggregation of body mass index. Eur $J$ Epidemiol 2012;27:53-61.

27. Hart C, McConnachie A, Upton M, et al. Risk factors in the midspan family study by social class in childhood and adulthood. Int $J$ Epidemiol 2008;37:604-14.

28. http://www.ons.gov.uk/ons/rel/family-demography/family-size/2012/ family-size-rpt.html

29. World Health Organisation. Measuring obesity: classification and description of anthropometric data. Copenhagen: WHO, 1989. (Nutr UD, EUR/ICP/NUT 125.).

30. Lean ME, Han TS, Morrison CE. Waist circumference indicates the need for weight management. BMJ 1995;311:158-61. 
31. Rose GA. The diagnosis of ischaemic heart pain and intermittent claudication in field surveys. Bull World Health Organ 1962;27:645-58.

32. Gunnell D, Whitley E, Upton MN, et al. Associations of height, leg length, and lung function with cardiovascular risk factors in the Midspan Family Study. J Epidemiol Community Health 2003:57:141-6.

33. Han TS, Lee DM, Lean ME, et al. EMAS Study Group. Associations of obesity with socioeconomic and lifestyle factors in middle-aged and elderly men: European Male Aging Study (EMAS). Eur J Endocrinol 2015;172:59-67.

34. Visscher PM, Hill WG, Wray NR. Heritability in the genomics era-concepts and misconceptions. Nat Rev Genet 2008;9:255-66.

35. Acock AC. Working with missing values. J Marriage Fam 2005;67:1012-28.

36. Grant I, Fischbacher C, Whyte B. Obesity in Scotland: an epidemiology briefing. Edinburgh: Scottish Public Health Observatory Collaboration, ISD, 2007.

37. Vlassopoulos A, Combet E, Lean ME. Changing distributions of body size and adiposity with age. Int J Obes 2013;38:857-64.

38. Perez-Pastor EM, Metcalf BS, Hosking J, et al. Assortative weight gain in mother-daughter and father-son pairs: an emerging source of childhood obesity. Longitudinal study of trios (EarlyBird 43). Int J Obes 2009;33:727-35.

39. Bouchard C, Tremblay A, Després JP, et al. The response to long-term overfeeding in identical twins. $N$ Engl J Med 1990;322:1477-82.

40. Wardle J, Carnell S, Haworth CM, et al. Evidence for a strong genetic influence on childhood adiposity despite the force of the obesogenic environment. Am J Clin Nutr 2008;87:398-404.

41. Lean ME. Childhood obesity: time to shrink a parent. Int J Obes 2010;34:1-3.

42. Loos RJ, Yeo GS. The bigger picture of FTO: the first GWAS-identified obesity gene. Nat Rev Endocrinol 2014;10:51-61.

43. Hofker M, Wijmenga C. A supersized list of obesity genes. Nat Genet 2009;41:139-40.
44. Elks CE, den Hoed M, Zhao JH, et al. Variability in the heritability of body mass index: a systematic review and meta-regression. Front Endocrinol (Lausanne) 2012;3:29.

45. Wang L, Mamudu HM, Alamian A, et al. Independent and joint effects of prenatal maternal smoking and maternal exposure to second-hand smoke on the development of adolescent obesity: a longitudinal study. J Paediatr Child Health 2014;50:908-15.

46. Rehan VK, Liu J, Sakurai R, et al. Perinatal nicotine-induced transgenerational asthma. Am J Physiol Lung Cell Mol Physiol 2013;305:L501-7.

47. Upton MN, Smith GD, McConnachie A, et al. Maternal and personal cigarette smoking synergize to increase airflow limitation in adults. Am J Respir Crit Care Med 2004;169:479-87.

48. Markunas CA, Xu Z, Harlid S, et al. Identification of DNA methylation changes in newborns related to maternal smoking during pregnancy. Environ Health Perspect 2014;122:1147-53.

49. Oken E, Taveras EM, Kleinman KP, et al. Gestational weight gain and child adiposity at age 3 years. Am J Obstet Gynecol 2007; 196:322.e1-8.

50. Oken E, Rifas-Shiman SL, Field AE, et al. Maternal gestational weight gain and offspring weight in adolescence. Obstet Gyneco 2008;112:999-1006.

51. Mamun AA, O'Callaghan M, Callaway L, et al. Associations of gestational weight gain with offspring body mass index and blood pressure at 21 years of age: evidence from a birth cohort study. Circulation 2009:119:1720-7.

52. Fraser A, Tilling K, Macdonald-Wallis C, et al. Association of materna weight gain in pregnancy with offspring obesity and metabolic and vascular traits in childhood. Circulation 2010;121:2557-64.

53. Drake AJ, Reynolds RM. Impact of maternal obesity on offspring obesity and cardiometabolic disease risk. Reproduction 2010;140:387-98.

54. Macintyre S, Sooman A. Non-paternity and prenatal genetic screening. Lancet 1991;338:869-71.

55. Griffiths AJF, Miller JH, Suzuki DT, et al. An introduction to genetic analysis. 7th edn. New York: W. H. Freeman, 2000. 